\title{
New Multidisciplinary Approach of Conservative Surgical Management of Placenta Percreta Antenatally Diagnosed
}

\author{
Berthelot-Ricou $\mathbf{A}^{1,2^{*}}$, Villot $\mathbf{A}^{1,3}$, Bernard $\mathbf{J}^{1,4}$, Eggermont-Gavage $\mathbf{J}^{1}$, Birsan-Frances $\mathbf{A}^{1}$ and Von Theobald $\mathbf{P}^{1,2}$ \\ ${ }^{1}$ Department of Gynecology, Obstetrics, Saint Denis Reunion Island, France \\ ${ }^{2}$ Perinatal study center of Indian Ocean (CEPOI), CHU La Reunion, 97448 Saint Pierre Reunion Island, France \\ ${ }^{3}$ Department of Gynecology, Obstetrics CHU Caen, 14033 Caen, France \\ ${ }^{4}$ Department of Gynecology, Obstetrics CHU Paule-de-Viguier, Toulouse, France
}

"Corresponding author: Berthelot-Ricou A, Department of Gynecology, Obstetrics, CHU La Reunion, CH Felix Guyon, 97405 Saint Denis Reunion Island, France, Tel: 33 692393412; E-mail: anais.berthelot@chu-reunion.fr

Rec date: Oct 08, 2013; Acc date: Jun 07, 2014; Pub date: June 09, 2014

Copyright: (c) 2014 Berthelot-Ricou A, et al. This is an open-access article distributed under the terms of the Creative Commons Attribution License, which permits unrestricted use, distribution, and reproduction in any medium, provided the original author and source are credited.

\begin{abstract}
Background: Placenta percreta, accreta, increta and transcreta are abnormal placentation adherence (APA), significantly associated with high maternal morbidity and mortality. When APA is suspected antenatally there are two current recommended alternatives: a radical treatment by planned cesarean-hysterectomy or a conservative management leaving the placenta in place with secondary uterine devascularization by embolisation, in aim to preserve fertility but at the cost of heavy monitoring and possibly severe complications and secondary hysterectomy. A third option could be considered when APA is antenatally diagnosed. This is a multidisciplinary planned management, consisting in per operative placental localization and delivery of the fetus via transverse uterine incision above the upper edge of the placenta. Then pelvic devascularization by inflation of internal iliac artery balloons preoperatively inserted is established and excision of the accreta part of the placenta followed by reconstruction of the uterine wall defect with healthy myometrium is performed.
\end{abstract}

Principe of the work: We evaluated the management and outcome of all APA diagnosed between January $1^{\text {st }}$ 2012 and 31 July 2013, in a Reunion Island tertiary care center, and describe our first case of placenta percreta managed according to this new multidisciplinary conservative alternative technique.

Statement of main conclusion: 7 cases of APA occurred during the study period, and have been systematically complicated of severe Post-Partum Hemorrhage (PPH) and hysterectomy in four cases.

Train finding: This first case report of multidisciplinary planned CS and conservative management of a placenta percreta was also the first one uncomplicated to $\mathrm{PPH}$, transfusion or hysterectomy, in our service since 2 years. This new alternative seems very encouraging, must be available as soon as possible and should be evaluated prospectively.

Keywords: Abnormal placental adherence (APA); Placenta accreta/ increta/percreta; post partum hemorrhage $(\mathrm{PPH})$; Conservative treatment; Myometrial excision

\section{Introduction}

Placenta percreta like accreta, increta and transcreta is abnormal placentation adherence (APA) due to the lack of chorionic decidual space resulting in a penetration of the placenta into the myometrium, the serosa and up to adjacent organs such as the bladder, the broad ligament or the colon [1]. It happens in $1 / 10000$ delivery according to international literature [2,3]. APA is significantly associated with severe obstetric complications involving the vital prognosis of patients (severe bleeding, multiple transfusions, per partum hysterectomy and death....).

The steady increase of caesarean sections [4], maternal age, IVF [3], voluntary abortions by curettage and are all known risk factors that may increase the incidence of APA $[5,6]$.
Prenatal diagnosis of these APA is based on an argument beam: anamnesis, ultrasound (US) and MRI to determine the likelihood of placental abnormality [6,7], with a sensitivity of 78 to $93 \%$ and a specificity of 67 to $71 \%$ for US, and respectively 67 to $80 \%$ and 50 to $65 \%$ for MRI $[8,9]$.

In case of strong diagnostic suspicion, the recommended standard care is a planned cesarean-hysterectomy, without attempted to remove placenta, in a tertiary care center [10].

This radical load prevents serious bleeding complications but compromise definitely the patient fertility. A second alternative offers a possibility of fertility preservation. It is a conservative care which consists in leaving the whole placenta in place without attempt to remove then to perform uterine arteries embolization for uterine devascularization in order to get a progressive necrosis of the placenta. This conservative treatment offers the possibility of a subsequent pregnancy, but needs a close and long follow up and side effects (severe hemorrhage, intrauterine infections...), that patients should be warned about and sometimes, secondary hysterectomy is required [11]. 
Citation: Berthelot-Ricou A, Villot A, Bernard J, Eggermont-Gavage J, Birsan-Frances A, et al. (2014) New Multidisciplinary Approach of Conservative Surgical Management of Placenta Percreta Antenatally Diagnosed. Surgery Curr Res 4: 195. doi: 10.4172/2161-1076.1000195

Page 2 of 5

These two alternatives are not satisfactory; a third option could allow both preserving fertility and avoiding the heavy follow-up of conservative treatment with placenta remaining in situ. In case of suspected diagnosis of placenta percreta, Chandraharan et al. [12] have recently published 4 cases about "Triple-P procedure ». This management involves per operative placental localization and delivery of the fetus via transverse uterine incision above the upper border of the placenta; pelvic devascularization; and placental non-separation with myometrial excision and reconstruction of the uterine wall incision. This procedure compared to hysterectomy can minimize maternal morbidity and mortality (blood loss, urinary tract injury...).

\section{Study Aim}

This study reports a retrospective analysis of the management of all cases of APA antenatally suspected or diagnosed per-CS between January $1^{\text {st }} 2012$ and 31 July 2013, and describes our first case management of placenta percreta with the new multidisciplinary planned conservative technique.

\section{Methods}

\section{Retrospective study}

We asked the department of medical informatics to identify all cases of deliveries and/or Caesarean Sections (CS) and/or postpartum hemorrhage and / or placenta previa and/or per partum hysterectomy. Then we isolated from medical records analyze, all cases of APA diagnosed on the pathological examination of the placenta or the hysterectomy part, between 1 January 2012 and 31 July 2013, in a tertiary maternity care facility (Felix Guyon Hospital, University Hospital of Reunion Island, France).

\section{Case report}

A 31 years old woman, with an history of 2 CS for placental abruption at 28 and 32 weeks of gestation (WG) whose two children died in the neonatal period, was transferred at 32 WG from the Mamoudzou hospital (Mayotte, France) for suspicion of placenta percreta.

The ultrasonography showed a placenta previa bipartita with multiple placenta lacunae and hypervascularisation of the adjacent bladder wall (Figure 1a). MRI suspected also the diagnostic of placenta percreta (Figure 1b-1d). A cystoscopy carried at $33 \mathrm{WG}$ excluded the transcreta placenta diagnosis.

The patient has been clearly informed of her APA and the the hemorrhagic risk. Then the different possibilities: radical or conservative treatment were exposed. Because of her origin (a little island near Mayotte island, France) the conservative treatment leaving the whole placenta in place was avoided. Cesarean hysterectomy was the only possibility excepted of the third option.

The three specialist (radiologist, anesthetist and gynecologist) explained and wrote the conduct of procedure and obtained her consent.

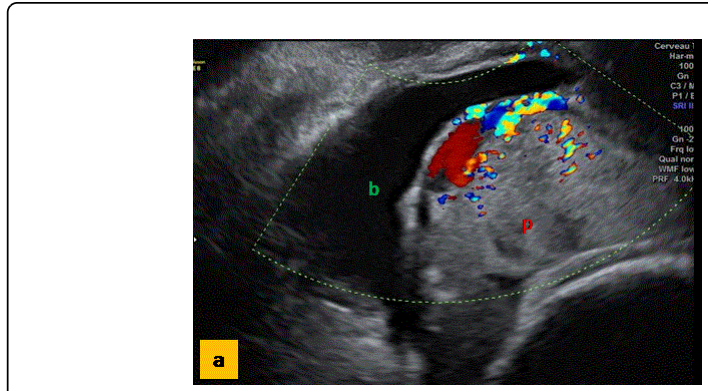

Figure 1a: Adjacent bladder wall

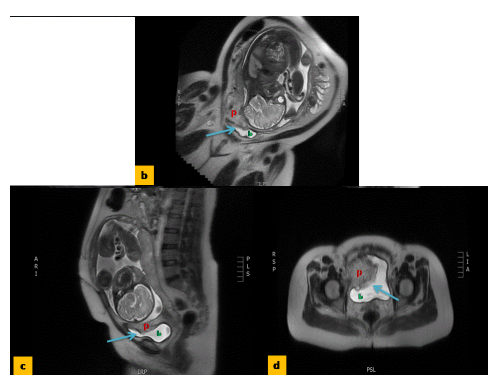

Figure 1b-d: Placenta percreta

We planned CS at 35 WG with anesthesia and interventional radiology teams. The intervention was performed on the X-ray table. The first step of the process was the establishment of internal iliac artery balloon catheterization under fluoroscopic control. Secondly we performed the CS, under general anesthesia [13]. The pre-operative ultrasound and MRI localized very well the upper border of placental (Figure 1c) so we did not need to make peri-operative US placental localization. On entry into the peritoneal cavity, the anterior percreta area was immediately obvious (Figure 2) and an area of sub-serous uterine rupture on four centimeters to the left of the percreta area was spotted. We made a transverse hysterotomy above the upper edge of the placenta and gave birth to a living boy weighing $2255 \mathrm{~g}$. At the delivery 10 UI of ocytocin IV were injected then the radiologist inflated prophylactically the balloons for pelvic devascularization before any action on the placenta. Partial abruption spontaneously occurred for its posterior portion, due to the uterine contraction. We gently loosened the placenta with the exception of the percreta area on the right side area of the lower segment (Figure 3a). The placenta was ligated and sectioned respecting the percreta area. After verification of the absence of transcreta vessels on the bladder this one was dissected away and the myometrial wall excised with $1-\mathrm{cm}$ healthy margin of myometrium around the percreta area (Figure $3 \mathrm{~b}$ ). The myometrial area with sub serous uterine rupture has been excised and sutured to consolidate the anterior myometrial wall. And finally we sutured the myometrial defect with a vertical layer of vicryl 1 stitches and hysterotomy in the usual way by a single transversal layer (Figure 4). The balloons were deflated 2 hours after waking up. There was no post-partum hemorrhage ( $\mathrm{PPH}$ ), the total blood loss of $500 \mathrm{ml}$ and the patient has not been transfused. Post-operative care was similar to a normal CS. 
Citation: Berthelot-Ricou A, Villot A, Bernard J, Eggermont-Gavage J, Birsan-Frances A, et al. (2014) New Multidisciplinary Approach of Conservative Surgical Management of Placenta Percreta Antenatally Diagnosed. Surgery Curr Res 4: 195. doi: 10.4172/2161-1076.1000195

Page 3 of 5

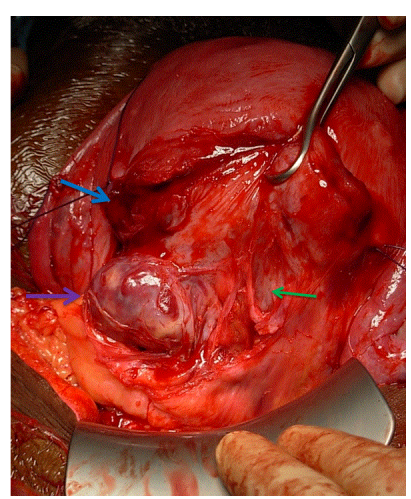

Figure 2: Anterior percreta area

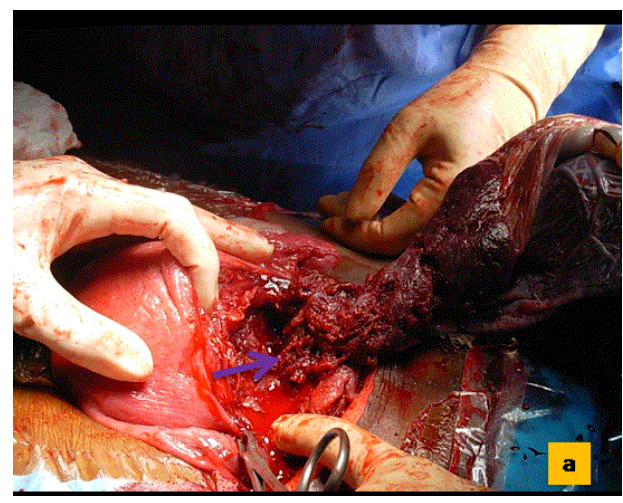

Figure 3a: Percreta area on the right side area of the lower segment

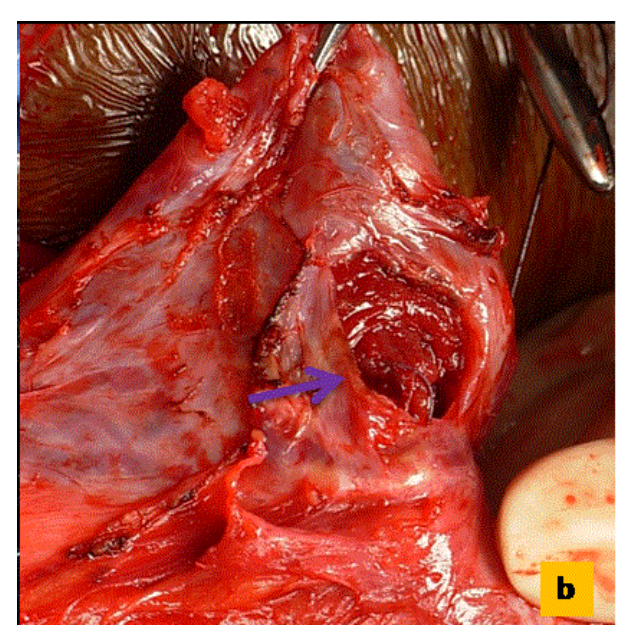

Figure 3b: Healthy margin of myometrium around the percreta area

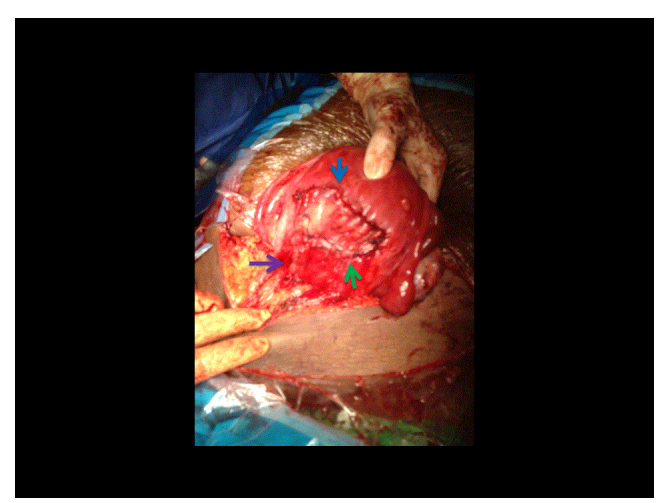

Figure 4: Single transversal layer

\section{Results and Discussion}

\section{Retrospective analysis: main findings}

During the study period, there were a total of 3657 births, including 835 CS $(22.8 \%)$ in our center.

We selected seven cases of APA. All of them were associated with placenta previa and birth occurred by CS (with trans-placental hysterotomy in 5 cases) under spinal anesthesia completed secondary with general anesthesia when PPH started. APA was suspected antenatally just for two cases (where caesarean section was scheduled) and the five other were diagnosed per CS performed in emergency. There was an attempt to remove placenta in all cases and CS was systematically complicated of severe hemorrhage (with an average blood loss of $2071 \mathrm{ml} \pm 2121 \mathrm{ml}$ ) and poly-transfusion of labile blood products. The Table 1 summarizes the characteristics of the population studied and the hemorrhage management. Hysterectomy for maternal rescue was performed in 4 cases (including 2 cases suspected antenatally) 2 had bladder injury but no maternal deaths occurred.

\section{Discussion}

It should be noted that the incidence of APA in our center (1.9 per 1,000 births and 8 per 1000 CS) is nearly 20 times more than in the recent the literature [3]. The Analysis of the management and outcome of APA during the last two years in our maternity is not satisfactory. On the one hand, all cases highlight a major maternal morbidity with severe systemic bleeding complications requiring transfusion (sometimes massive) of labile blood products. And on the other hand, no patient was conservatively managed in our center. This choice of management is probably explained by the inability to monitor patients or by the impossibility of achieving emergency embolization. Prevention of PPH is a public health priority in France, and the high incidence of APA in our population in Reunion Island, increase our interest in APA and its management. In the 2 cases of APA suspected prenatally, no attempt of preventive measures of postpartum hemorrhage were made and these two cases were complicated by severe bleeding and ended with a hysterectomy. 
Citation: Berthelot-Ricou A, Villot A, Bernard J, Eggermont-Gavage J, Birsan-Frances A, et al. (2014) New Multidisciplinary Approach of Conservative Surgical Management of Placenta Percreta Antenatally Diagnosed. Surgery Curr Res 4: 195. doi: 10.4172/2161-1076.1000195

Page 4 of 5

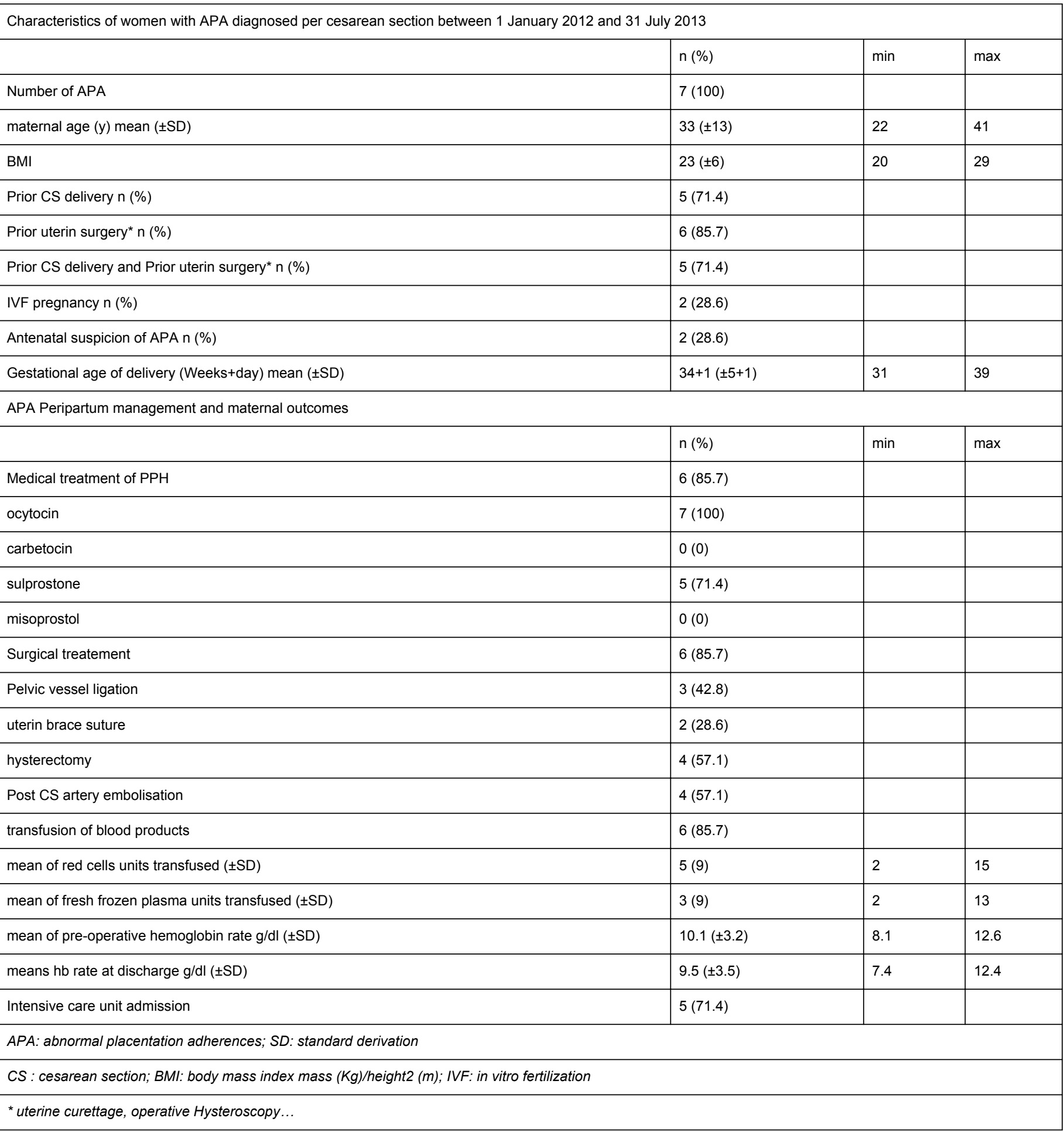

Table 1: Characteristics of the population studied and the hemorrhage management

The radical treatment of cesarean-hysterectomy should be performed according to international recommendations $[10,14]$ without attempt to remove placenta. It leaves no possibility of subsequent fertility in patients.
The evaluation of our professional practices and of our poor results has allowed us to implement corrective measures. From August 2013 we decided to change our support and tested a multidisciplinary approach involving interventional radiologists-anesthesiologists and gynecologist surgeons [12]. The surgical procedure is planned with the 
Citation: Berthelot-Ricou A, Villot A, Bernard J, Eggermont-Gavage J, Birsan-Frances A, et al. (2014) New Multidisciplinary Approach of Conservative Surgical Management of Placenta Percreta Antenatally Diagnosed. Surgery Curr Res 4: 195. doi: 10.4172/2161-1076.1000195

Page 5 of 5

interventional radiologists and the anesthesiologists. Intravascular balloons are set into the internal iliac arteries before skin incision. They are ready for inflation to devascularize the uterus if needed. After fetal extraction, the accreta part of the placenta is excised with the underlying myometer aiming to minimize the risk of post-partum hemorrhage and complications while keeping the possibility of future pregnancy. Our first case reported here of this new conservative approach of placenta percreta treatment (antenatally suspected), was a success since had no $\mathrm{PPH}$ and uterine preservation was possible without placenta left inside.

We are well aware of the need of further prospective studies on this technique, in order to provide accurate statistical evidence on its performance and side effect evaluation of this technique (including systematic prophylactic pelvic devascularization [15]).

Actually, we're setting up a prospective multicenter study to evaluate this new surgical alternative aiming to reduce maternal morbidity and allow the patient to subsequent fertility, without the inconvenience and complications of long-term follow-up of complete placenta left in utero.

\section{Acknowledgements}

Dr Emmanuel Chirpaz from the department of medical informatics for giving us the listing necessary to create the database andfor echographic iconography.

\section{References}

1. Garmi G, Salim R (2012) Epidemiology, etiology, diagnosis, and management of placenta accreta. Obstet Gynecol Int 2012: 873929.

2. Daskalakis G, Anastasakis E, Papantoniou N, Mesogitis S, Theodora M, et al. (2007) Emergency obstetric hysterectomy. Acta Obstet Gynecol Scand 86: 223-227.

3. Fitzpatrick KE, Sellers S, Spark P, Kurinczuk JJ, Brocklehurst P, et al. (2012) Incidence and risk factors for placenta accreta/increta/percreta in the UK: a national case-control study. PLoS One 7: e52893.
4. MacDorman MF, Menacker F, Declercq E (2008) Cesarean birth in the United States: epidemiology, trends, and outcomes. Clin Perinatol 35: 293-307, v.

5. Wu S1, Kocherginsky M, Hibbard JU (2005) Abnormal placentation: twenty-year analysis. Am J Obstet Gynecol 192: 1458-1461.

6. Wortman AC, Alexander JM (2013) Placenta accreta, increta, and percreta. Obstet Gynecol Clin North Am 40: 137-154.

7. Héquet D, Ricbourg A, Sebbag D, Rossignol M, Lubrano S, et al. (2013) [Placenta accreta: screening, management and complications]. Gynecol Obstet Fertil 41: 31-37.

8. Lim PS, Greenberg M, Edelson MI, Bell KA, Edmonds PR, et al. (2011) Utility of ultrasound and MRI in prenatal diagnosis of placenta accreta: a pilot study. AJR Am J Roentgenol 197: 1506-1513.

9. Dwyer BK, Belogolovkin V, Tran L, Rao A, Carroll I, et al. (2008) Prenatal diagnosis of placenta accreta: sonography or magnetic resonance imaging? J Ultrasound Med 27: 1275-1281.

10. Fitzpatrick KE, Sellers S, Spark P, Kurinczuk JJ, Brocklehurst P, et al. (2014) The management and outcomes of placenta accreta, increta, and percreta in the UK: a population-based descriptive study. BJOG 121: 62-70.

11. Sentilhes L, Goffinet F, Kayem G (2013) Management of placenta accreta. Acta Obstet Gynecol Scand 92: 1125-1134.

12. Chandraharan E, Rao S, Belli AM, Arulkumaran S (2012) The Triple-P procedure as a conservative surgical alternative to peripartum hysterectomy for placenta percreta. Int J Gynaecol Obstet 117: 191-194.

13. Kuczkowski KM (2011) A review of current anesthetic concerns and concepts for cesarean hysterectomy. Curr Opin Obstet Gynecol 23: 401-407.

14. Eshkoli T, Weintraub AY, Sergienko R, Sheiner E (2013) Placenta accreta: risk factors, perinatal outcomes, and consequences for subsequent births. Am J Obstet Gynecol 208: 219.

15. Bishop S, Butler K, Monaghan S, Chan K, Murphy G, et al. (2011) Multiple complications following the use of prophylactic internal iliac artery balloon catheterisation in a patient with placenta percreta. Int J Obstet Anesth 20: 70-73. 